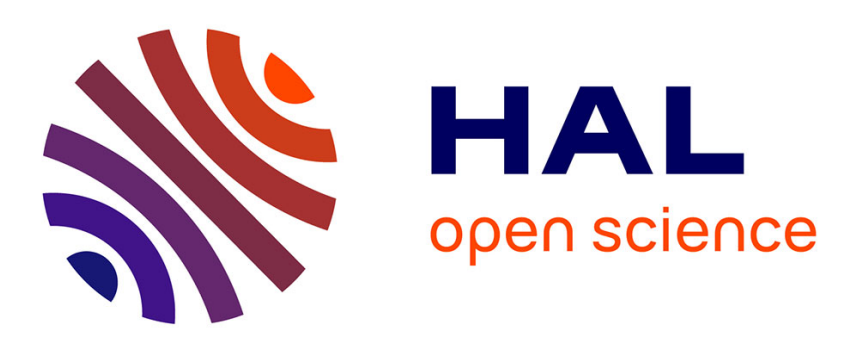

\title{
Characterization of the porosity of silicon nitride thin layers by Electrochemical Impedance Spectroscopy
}

Thomas Barrès, Bernard Tribollet, O. Stephan, H. Montigaud, M. Boinet, Y. Cohin

\section{- To cite this version:}

Thomas Barrès, Bernard Tribollet, O. Stephan, H. Montigaud, M. Boinet, et al.. Characterization of the porosity of silicon nitride thin layers by Electrochemical Impedance Spectroscopy. Electrochimica Acta, 2017, 227, pp.1 - 6. 10.1016/j.electacta.2017.01.008 . hal-01452732

\section{HAL Id: hal-01452732 \\ https://hal.science/hal-01452732}

Submitted on 2 Feb 2017

HAL is a multi-disciplinary open access archive for the deposit and dissemination of scientific research documents, whether they are published or not. The documents may come from teaching and research institutions in France or abroad, or from public or private research centers.
L'archive ouverte pluridisciplinaire HAL, est destinée au dépôt et à la diffusion de documents scientifiques de niveau recherche, publiés ou non, émanant des établissements d'enseignement et de recherche français ou étrangers, des laboratoires publics ou privés. 


\section{Characterization of the porosity of silicon nitride thin layers by}

\section{Electrochemical Impedance Spectroscopy}

T. Barrès ${ }^{\mathrm{a}}$, B. Tribollet ${ }^{\mathrm{b}}$, O. Stephan ${ }^{\mathrm{c}}$, H. Montigaud ${ }^{\mathrm{a}}$, M. Boinet ${ }^{\mathrm{d}}$, Y. Cohin ${ }^{\mathrm{e}}$.

${ }^{a}$ Surface du Verre et Interfaces UMR 125 CNRS/Saint-Gobain, 39 quai Lucien Lefranc 93303 Aubervilliers, France,

${ }^{b}$ Laboratoire LISE UMR 8235 CNRS/Université Paris VI UPMC,4, place Jussieu 75252 Paris CEDEX 5, France,

${ }^{c}$ Laboratoire de Physique des Solides UMR 8502 CNRS/Université Paris Sud,1 rue Nicolas Appert 91405 Orsay CEDEX, France,

${ }^{d}$ Saint-Gobain - Northboro Research \& Development Center, 9 Goddard Rd, Northborough, MA 01532, USA,

${ }^{e}$ Saint-Gobain Recherche, 39 quai Lucien Lefranc 93303 Aubervilliers, France.

Corresponding author:Thomas Barrès, thomas.barres@ saint-gobain.com, +33(0)148395618 


\begin{abstract}
Silicon nitride thin films are widely used as diffusion barriers within stacks in the glass industry but turn out to be porous at the nanometric scale. EIS measurements were conducted on SiNx thin layers deposited on a gold layer. An electrochemical model was established to fit the EIS measurementsmaking use of data from other complementary techniques. In particular, Transmission Electron Microscopy was performed on these thin layers to determine the diameter and the qualitative morphology of the pores. A quantitative determination of the through-porosity of the layer was deduced from the EIS model and was in good agreement with TEM measurements. Moreover, combining EIS with local observations enabled inhomogeneitiesin the layer to be probed by highlighting a specific region in the layer.
\end{abstract}

\title{
Keywords
}

Electrochemical Impedance Spectroscopy; Transmission Electron Microscopy; Porosity; Silicon Nitride; Thin Layer.

\section{Introduction}


Dielectric thin films have found many applications,including as insulators or diffusion masks inmicroelectronics [1] and antireflection coatings, beam splitters or polarizing elements in optical elements[2]. Their use is widespread as stacks of functionalized glazing layers inthe glass industry[3] to adjust the optical properties, prevent corrosion or act as barrier layersto diffusion. Silicon nitride thin layers are widely usedfor their good barrier properties $[4,5]$, and we focus on this material for our study.

The deposition of silicon nitride layers can be performed using several techniques. Dense and homogeneous layerscan be obtained by Plasma-Enhanced Chemical Vapor Deposition (PECVD)[6], but suffer hydrogen inclusion related to the precursors which are involved. Magnetron sputtering is extensively used in the glass industryand furnisheshigh-quality silicon nitride thin layers on large substrates $\left(3.2 \times 6 \mathrm{~m}^{2}\right)$ with reduced costs [7].

However, SiNx thin layers deposited by magnetron sputtering turn out to be porous at the nanometricscale [8]. The determination of this porosity is crucial to understanding the barrier properties of the layer. In the case of larger pores (micrometric scale), Ahnet al.have given a quantitative description of through-coating porosity using Electrochemical Impedance Spectroscopy (EIS) [9].

The aim of this study is to give a quantitative description of the structure at the nanometer scale of these silicon nitride thin layers deposited by magnetron sputtering. The investigation of the porosity is carried outby Electrochemical Impedance Spectroscopy (EIS). We 
combineEIS with local observations by Transmission Electron Microscopy (TEM) allowing us to determine the morphology of the pores in order to validate the electrochemical model.

\section{Experimental}

\subsection{Material deposition}

The working electrode studiedwas composed of a Glass/SiNx/NiCr/Au/SiNxmultilayer deposited on glass by magnetron sputtering. The base pressure in the chamber was $2 \times 10^{-6}$ mbar. The under layers of silicon nitride and nickel chromium prevent the diffusion of alkali from the glass and promote the adhesion of gold respectively. The gold layer is deposited by magnetron sputtering using a high purity gold target under a total pressure of $8 \mu \mathrm{bar}$ of Ar. Its thickness is set to $10 \mathrm{~nm}$. The deposition of $30 \mathrm{~nm}$ of SiNxon the gold is executed by reactive magnetron sputtering in the same chamber as for the gold. A2\%-aluminum-doped silicon target is sputtered in a gas mixture of $\mathrm{Ar}$ and $\mathrm{N}_{2}$ at a total pressure of $14 \mu \mathrm{bar}$ with fluxes of $180 \mathrm{sccm}$ and $52 \mathrm{sccm}$ respectively $\left(5.4 \mathrm{~W} / \mathrm{cm}^{2}, 100 \mathrm{kHz}\right)$. Thealuminum-doped targets do not crack under sputtering and generate fewer undesired particles in the chamber, thus reducing the brittleness of SiNx. Widely used in industrial production lines, they generateSiNx layers whose properties do not change from the case of deposition using a pure silicon target. [10]

The SiNx thin film characteristics such as layer thickness, composition, surface roughness and optical index have been measured. The layer thickness was estimated by masking a part of the substrate then measuring the step obtained after deposition by Atomic Force MicroscopyAFM (ICON Bruker). We measured a thickness $d$ of $30 \mathrm{~nm}$ for the SiNx layer. The surface 
roughness was also evaluated by AFMto have anRMS value of $1.6 \mathrm{~nm}$ on a 500x500 nm area.

The calibration of the deposition and the control of the reproducibility were provided by optical measurements (optical absorption and reflection spectrometry in the [250, $2500 \mathrm{~nm}]$ wavelength range). A density of $2.9 \mathrm{~g} / \mathrm{cm}^{3}$ was obtained for the sample via X-Ray Reflectometry (Bruker D5000, $\mathrm{CuK} \alpha(1,2)$ / scintillator, XRR). Finally, the composition of the film was determined by Electron Probe Micro Analysis (CamecaSXFive) on the same layer deposited on a Ge wafer; the layer composition is the following: 54.6 at.\% N, 40.9 at.\% Si, 3.2 at.\% $\mathrm{Al}$, and 1.3 at.\% $\mathrm{O}$.

\subsection{Electrochemical measurements}

A three-electrode electrochemical cell, filled with $0.5 \mathrm{M} \mathrm{Na} \mathrm{SO}_{4}$, was used in the electrochemical impedance measurements. The cell consists of a cylinder of PMMA (poly(methyl methacrylate))fixed on the sample surface,providing a working electrode area of $10 \mathrm{~cm}^{2}$. The electrical contact is made through $\mathrm{SiNx}$ on the gold layer by ultrasonic welding. A sheet resistance of $2.6 \Omega /$ sq was measured using a four-point probe. The imperfect transport of electrons in the $10 \mathrm{~nm}$ gold layer can induce a rather low resistance value which adds on to the electrolyte resistance value. A mercury-mercurous sulfate electrode and a 10 $\mathrm{cm}^{2}$ platinum cylindrical sheet are used as reference and counter electrode respectively. A Pt wire is inserted in series with a $47 \mathrm{nFcapacitor}$ connected to the reference electrode to avoid artefacts at high frequency due to the high impedance of the reference electrode [11].The impedance measurements were performed using a Biologic SP 300 device, operating in 
potentiostat mode at the corrosion potential.We used a $14 \mathrm{mV}$ peak-to-peak sinusoidal potential perturbation (10 $\mathrm{mV}$ RMS) whose frequency range extends from $100 \mathrm{kHz}$ to $1 \mathrm{mHz}$ with 11 points per decade. The sample was immersed 24 hours before the acquisition of the impedance spectra. The surface state of the sample was investigated by optical microscopy after measurement and showed no corrosion points or delaminated areas.

Data modeling was carried out using non-commercial software developed at the LISE CNRS, Paris, based on a simplex strategy. The program minimizes the function $\chi^{2}$ given below (equation 1).

$\chi^{2}=\sum_{i=1}^{n f}\left[\left(\frac{\operatorname{Re}\left(Z_{e, i}\right)-\operatorname{Re}\left(Z_{c, i}\right)}{0.005 .\left|Z_{e}\right|}\right)^{2}+\left(\frac{\operatorname{Im}\left(Z_{e, i}\right)-\operatorname{Im}\left(Z_{c, i}\right)}{0.005 .\left|Z_{e}\right|}\right)^{2}\right]$

With $n f$ the number of frequencies in the experimental spectra, $Z_{e}$ and $Z_{c}$ the experimental and calculated impedance respectively, and the 0.005 coefficient standing for an acceptable error of $0.5 \%$ between the experimental and the calculated spectra.

The reproducibility of the measurements was tested. Deviations from reproducibility can be observed between several deposited samples and the inhomogeneity of the deposition can be measured by EIS on the sample itself. Thus, the samples presented in this study come from the same batch and the tendencies emerging from the experimental results exceed the reproducibility errors.

\subsection{Transmission Electron Microscopy}


The SiNx layers were observed in cross section by Transmission Electron Microscopy (TEM) in bright-field mode after preparation of a thin lamella by Focused Ion Beam (FIB). These observations were carried out on an Akashi Topcon EM-002B microscope at $100 \mathrm{kV}$ with under-focused conditions (up to $50 \mathrm{~nm}$ in defocus).

The deposition of silicon nitride on commercial membranes (15 $\mathrm{nm}$ of silicon nitride support film deposited on a silicon wafer with nine windows of 100x100 $\mu \mathrm{m}^{2}$ ) allowed us to observe the layers in plan view. Scanning Transmission Electron Microscopy (STEM) measurements were performed in planview with a spherical aberration-corrected NION USTEM 200 instrument operated at an accelerating voltage of $100 \mathrm{kV}$. High-Angle Annular Dark-Field (HAADF) images were acquired.

\section{Theory}

The impedance of a dielectric layer can be represented by the series connection of several sets of Voigt elements (a resistor in parallel with a capacitor). [Figure 1]The schematic representation in figure 1 shows that the impedance tends towards a resistance at low frequency and towards a pure capacitance at high frequency.

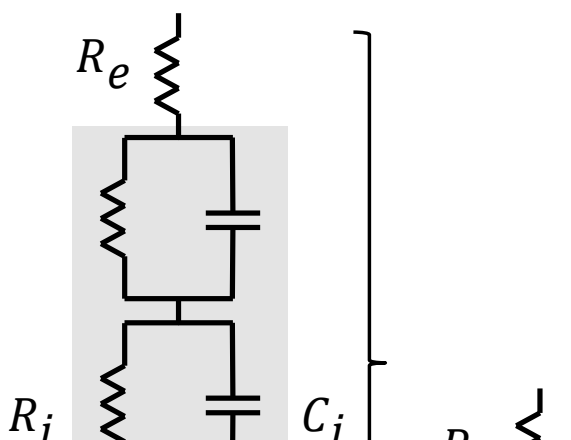


Figure 1 - Electrical circuit modelling the impedance of a dielectric layer. On the left is represented a set of Voigt elements (a resistance in parallel with a capacitance) in series. This set can be written as the sum of each Voigt element (right part of the figure).

To each of these Voigt elements is associated a slice of a given thickness $d x$. Thus the local resistance can be written as a function of the local resistivity $\rho(x)$ and of the thickness of the correlated slice, while the local capacitance can be expressed as a function of the local permittivity $\varepsilon(x)$, the vacuum permittivity $\varepsilon_{0}$, and of the thickness of the slice (equation2). The variable $x$ is set equal to 0 at the electrode/layer interface.

$R_{n}=\rho(x) d x \quad C_{n}=\varepsilon(x) \varepsilon_{0} / d x$

The local impedance can be written as afunction of the local resistivity and permittivity, and then the global impedance Zis deduced for a layer of thickness $d$ (equation 3).

$d Z=\frac{\rho(x) d x}{1+j \omega \rho(x) \varepsilon(x) \varepsilon_{0}} \quad Z=\int_{0}^{d} \frac{\rho(x) d x}{1+j \omega \rho(x) \varepsilon(x) \varepsilon_{0}}$ 
If the permittivity is independent of position, the impedance becomes:

$Z=\int_{0}^{d} \frac{\rho(x) d x}{1+j \omega \rho(x) \varepsilon \varepsilon_{0}}$

The impedance depends of the resistivity distribution in the layer. Two main distributions of resistivity are commonly presented in literature: the Young model [12] and the power-law distribution which was proposed by Hirschornet al. [13, 14].

Young proposed an exponential decay of the resistivity as a function of the local position along the direction normal to the surfacex. The resistivity for $x=0$ corresponds to the intrinsic value of the material $\rho_{0}$ and a characteristic length $l$ is introduced(equation 5).

$\rho(x)=\rho_{0} \exp (-x / l)$

With this distribution the integral can be written in the analytical form called the Young model (equation 6). This expression was used first by Schilleret al. [15] for the study of coatings and later by Nguyenet al. [16].

$Z_{c}(\omega)=\frac{-l}{j \omega \varepsilon \varepsilon_{0}} \ln \left[\frac{1+j \omega \varepsilon \varepsilon_{0} \rho_{0} e^{-d / l}}{1+j \omega \varepsilon \varepsilon_{0} \rho_{0}}\right]$

Since the Young model presents a variable phase across the range of frequency, this model cannot explain theConstant Phase Element (CPE) behavior found in some experiments. Thus Hirschornet al. [13, 14] proposed another model based on a power-law distribution of resistivity in the layer. The resistivity is expressed as a function of the thickness of the layer 
$d$, the depth $x$ in the layer and the limit values of the resistivity $\rho_{0}$ and $\rho_{d}$ at the interfaces

$x=0$ and $x=d$ respectively (equation 7 ).

$\frac{\rho}{\rho_{d}}=\left(\frac{\rho_{d}}{\rho_{0}}+\left(1-\frac{\rho_{d}}{\rho_{0}}\right)\left(\frac{x}{d}\right)^{\gamma}\right)^{-1}$

For a frequency $f<\left(2 \pi \varepsilon \varepsilon_{0} \rho_{d}\right)^{-1}$, the corresponding impedance is expressed as:

$Z_{c}(\omega)=\left(1+2.88 \gamma^{-2.375}\right) \frac{d \rho_{d}^{1 / \gamma}}{\left(\rho_{0}^{-1}+j \omega \varepsilon \varepsilon_{0}\right)^{(\gamma-1) / \gamma}}$

This expression shows a CPE behaviorwith a coefficient $\alpha=\gamma-1 / \gamma$ in the frequency domain $\left(2 \pi \varepsilon \varepsilon_{0} \rho_{0}\right)^{-1}<f<\left(2 \pi \varepsilon \varepsilon_{0} \rho_{d}\right)^{-1}$.

\section{Results and discussion}

The Nyquist and Bode diagrams of the impedance measurements of SiNxfilms on gold are presented in figure 2[Figure 2].
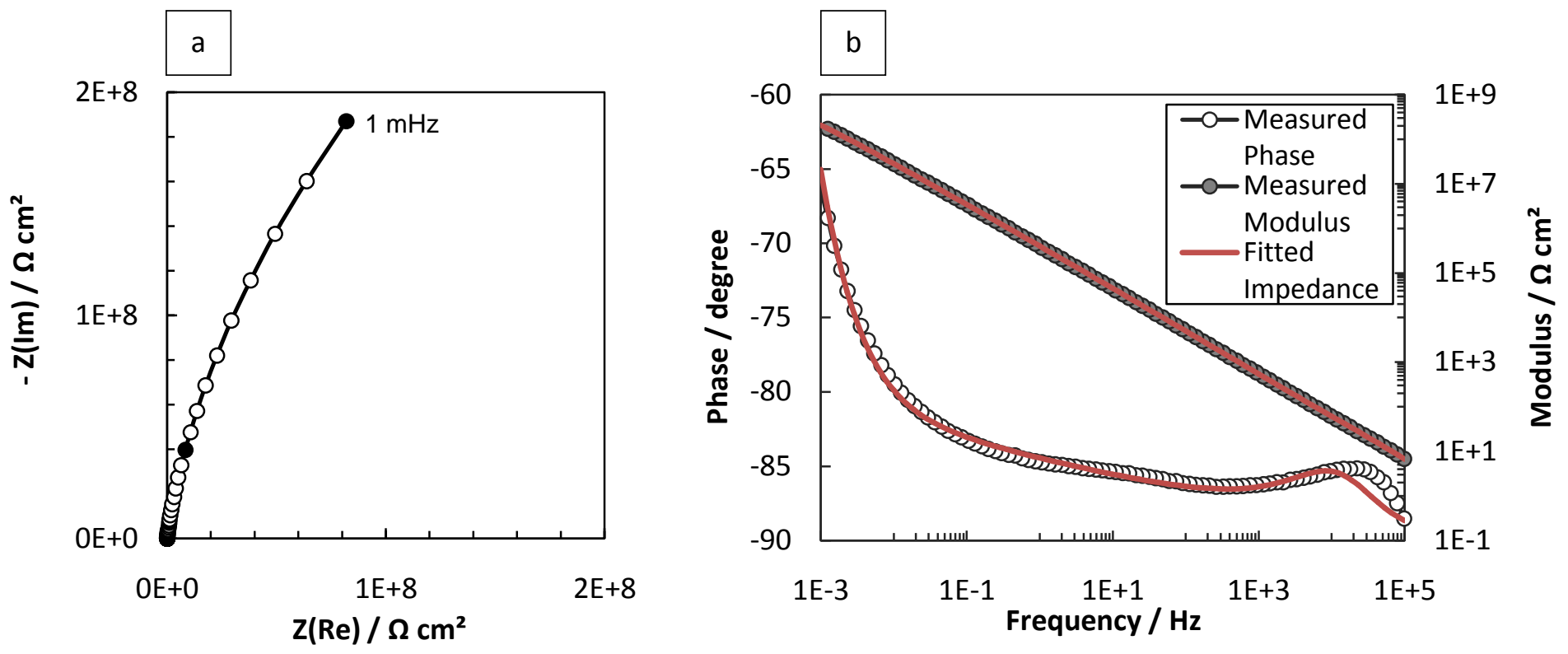
Figure 2 - Impedance spectra for $30 \mathrm{~nm} \mathrm{SiNx}$ on gold obtained in $0.5 \mathrm{M} \mathrm{Na}_{2} \mathrm{SO}_{4}$ at the corrosion potential. a.Nyquist plot of the impedance showing the dependence of $-Z(\operatorname{Im})$ vs $Z(R e)$. In insert, an enlargement of the scale showing the electrolyte resistance value. b. The experimental Bode plot is presented corrected for the ohmic drop in white and gray circles for the phase and the modulus of the impedance respectively. The fitted Bode plot obtained from the optimization (based on a simplex method) of the electrical circuit model parameters is represented in red lines.

The Bode diagram obtained shows a slow decrease in the phase across the [100 $\mathrm{mHz}, 1 \mathrm{kHz}]$ frequency range. The electrolyte resistance value was determined by the intersection of the Nyquist plot with the real axis (insert in figure 2a).

\subsection{Cole-Cole plot}

In order to obtain the permittivity of the $\mathrm{SiNx}$, the layer was considered as a complex capacitance and studied in a Cole-Cole representation [17]. The Cole-Cole plot presented in figure3 [Figure 3] was obtained from the impedance spectra and the electrolyte resistance determination (equation9).

$$
C(\omega)=\frac{1}{j \omega\left(Z(\omega)-R_{e}\right)}
$$




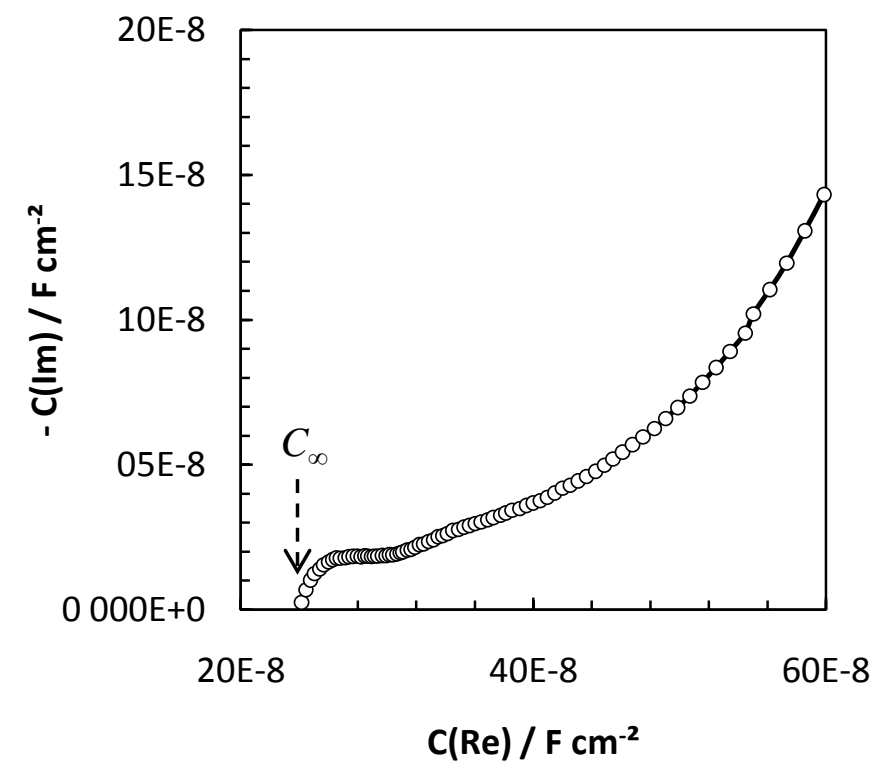

Figure 3 - Cole-Cole plot obtained from the impedance measurement of a $30 \mathrm{~nm} \mathrm{SiNx}$ layer representing the complex capacitance $\mathrm{C}$ as $-C(\operatorname{Im})$ vs $C(R e)$. The $C_{\infty}$ value stands for the extrapolation to high frequency of the plot (intersection with the real axis).

The extrapolation of the real part of the capacitance to high frequency leads to a value of $0.24 \mu \mathrm{F} / \mathrm{cm}^{2}$. The thickness of the layer is well determined from the calibration of the deposition $(30 \mathrm{~nm})$, so the permittivity value is easily deduced from the capacitance using equation 10. [18]

$\varepsilon=\frac{d C_{\infty}}{\varepsilon_{0}}$

with $\varepsilon$ the permittivity of the layer, $\varepsilon_{0}$ the vacuum permittivity, $d$ the thickness of the layer, and $C_{\infty}$ the extrapolation at high frequency of the capacitance.

We found a permittivity of 8.1 for this $30 \mathrm{~nm}$ SiNx layer, which is in good accordance with the literature.[7, 19] 


\subsection{Electrical equivalent model}

Since the phase across the $[100 \mathrm{mHz}, 1 \mathrm{kHz}]$ frequency range is not constant and does not correspond to a CPE, the Young model seems to be more appropriate than a power-law model to fit the our datain this frequency range. Thus, the global model used is composed of a Young impedance in parallel with a branch composed of a pore resistance in series witha CPE representing the electrical double layer at the bottom of the through-pores.

The first branch of the model is described by the Young impedance. This impedance is related to a resistivity gradient due to the distribution of non-through-pores in the axial direction $x$ in the layer (equation 5).

The second branch of the model describes the impedance in the through-pores, using a CPE $\left(\mathrm{Q}_{\mathrm{dl}}, \alpha_{\mathrm{dl}}\right)$ for the double layer at the bottom of the pores in series with a pore resistance. [Figure 4].The gold electrode is considered as a blocking electrode since the value of the charge transfer resistance is substantially higher than the impedance of the CPE in the frequency range of the measurements.

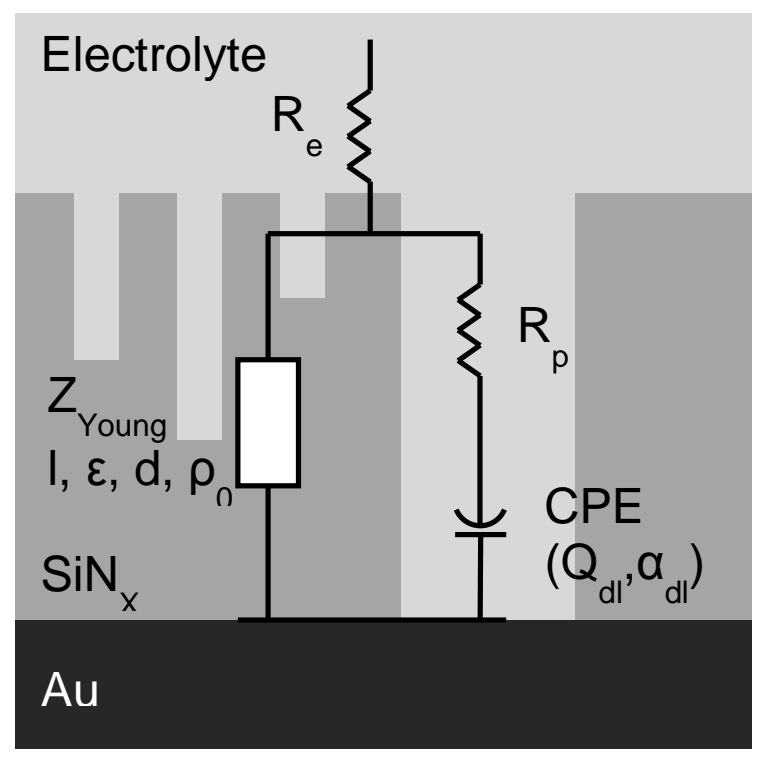


Figure 4 - Equivalent circuit used to describe the impedance of a $30 \mathrm{~nm}$ SiNx layer. The Young parameters are the intrinsic resistivity of the layer $\rho_{0}$, a characteristic length $l$, the permittivity of the layer $\varepsilon$, and the thickness $d$. The right branch of the impedance is constituted by a pore resistance $\left(R_{p}\right)$ in series with the electrical double layer $\operatorname{CPE}\left(Q_{d l}, \alpha_{d l}\right)$.

The experimental data and the result of the fittingmodel of the impedance arerepresented in a Bode plot (Figure 2b): the model is in good agreement with the data,with a $\chi^{2}$ value of 1.08 . The high frequency region (from $10 \mathrm{kHz}$ to $100 \mathrm{kHz}$ ) is less compatible with the model, since the bump on the phase is not well fitted. However, the impedance modulus corrected for the ohmic drop tends to zero at high frequency, which implies a concomitant reduction of the signal-to-noise ratio. Hence, the confidence in the goodness of the fit in the high frequency region is hard to evaluate due to these low values of the impedance modulus.

The parameters used in the regression are given in the table 1. [Table 1] The value of $4.110^{14}$ $\Omega \mathrm{cm}$ determined for the intrinsic resistivity corresponds to those found in literature for magnetron-sputtered $\mathrm{Si}_{3} \mathrm{~N}_{4}$ [20]. The pore resistance shows a relatively low value which may indicate a high through-porosity - see next section.

\begin{tabular}{ccc|cccccc||c}
\hline $\begin{array}{c}\mathrm{d} \\
(\mathrm{nm})\end{array}$ & $\begin{array}{c}\mathrm{R}_{\mathrm{e}} \\
\left(\Omega \mathrm{cm}^{2}\right)\end{array}$ & $\varepsilon$ & $\begin{array}{c}\rho_{0} \\
(\Omega \mathrm{cm})\end{array}$ & $\begin{array}{c}1 \\
(\mathrm{~cm})\end{array}$ & $\begin{array}{c}\mathrm{Q}_{\mathrm{dl}} \\
\left(\Omega^{-1} \mathrm{~cm}^{-2} \mathrm{~s}^{\alpha}\right)\end{array}$ & $\alpha_{\mathrm{dl}}$ & $\begin{array}{c}\mathrm{R}_{\mathrm{p}} \\
\left(\Omega \mathrm{cm}^{2}\right)\end{array}$ & $\chi^{2}$ & $\begin{array}{c}\mathrm{C}_{\mathrm{dl}}\left(\mathrm{F} . \mathrm{cm}^{-}\right. \\
2\end{array}$ \\
\hline 30 & 43.8 & 8.1 & $4.110^{14}$ & $3.010^{-6}$ & $2.210^{-7}$ & 0.85 & 280 & 1.08 & $3.9 .10^{-8}$ \\
\hline AFM & Nyquist & Cole-Cole & Fit & Fit & Fit & Fit & Fit & & Brug \\
\hline
\end{tabular}


Table 1 - Results of the measured impedance fitting for $\mathrm{SiNx}$ in $0.5 \mathrm{M} \mathrm{Na}_{2} \mathrm{SO}_{4}$. The layer thickness was measured by AFM, the electrolyte resistance was determined from the Nyquist diagram and the permittivity was obtained from the extrapolation of the Cole-Cole representation at high frequency. All the other parameters are fitted with the electrical equivalent circuit presented in figure 4 . The value of $\chi^{2}$ is obtained for an estimated error of $0.5 \%$. The effective value of the electrical double layer determined with the Brug formula is reported in the last column.

\subsection{Quantification of the through-porosity}

The CPE used for the double layer model is assumed to correspond to a surfacevariation of the time constant. Indeed, the electric double layer is located at the bottom of throughporosity on the conductive accessible electrode surface. Thus, the formula proposed by Brug et al. [21] can be applied to this system in order to extract the effective capacitance value of the electric double layer. By dividing the effective capacitance value obtained at the bottom of the through-pores by the value determined on the gold electrode without the layer, we are able to give the fraction of electrode accessible due to through-porosity.

EIS measurementswere made on the gold electrode without the SiNx layer. [Figure 5] The Bode diagram is presented across the frequency range $[0.01 ; 100 \mathrm{~Hz}]$. The frequency domain was selected in order to model the electrical double layer formed on the gold electrode. Furthermore, the high frequency limit was set such that the measured modulus value corresponds to the electrolyte resistance, to avoid any artefact. The result is a constant phase in this frequency range which is modelled by a CPE for the electric double layer. 


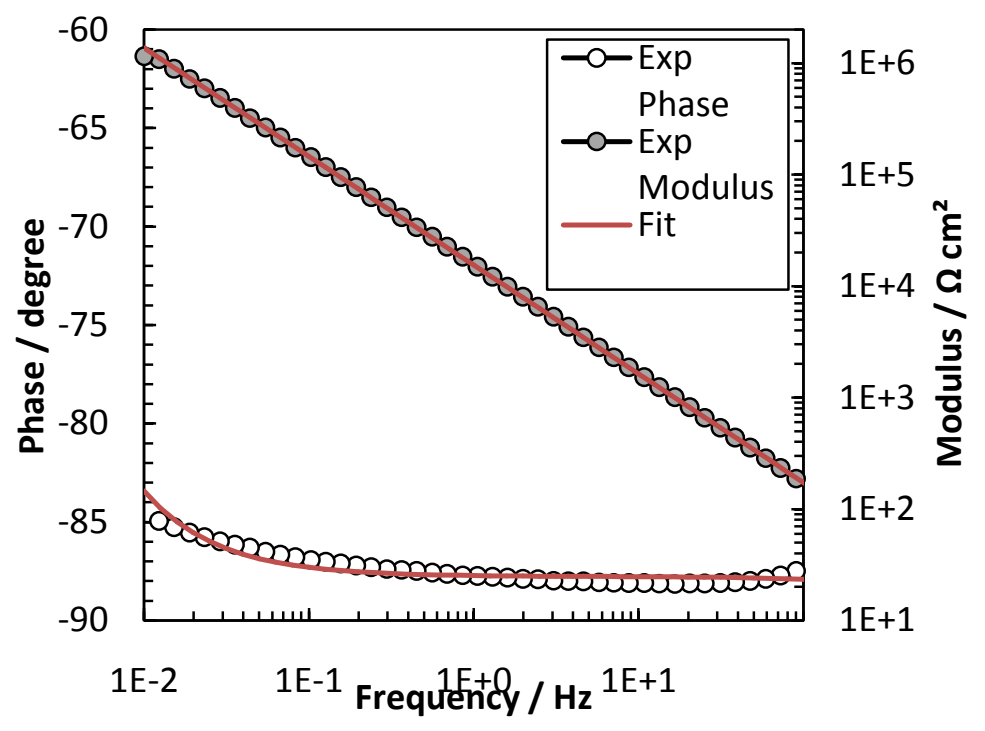

Figure 5 - Bode plot of the measured impedance spectra in $0.5 \mathrm{M} \mathrm{Na}_{2} \mathrm{SO}_{4}$ of a $10 \mathrm{~nm}$ gold layer deposited on glass. The white and gray circles stand for the experimental phase and modulus respectively. The fitted plot is represented in red lines.

We applied the following Brug formula on gold with and without the SiNx layer, neglecting the charge transfer resistance in the system.

$C_{e f f}=Q_{d l}^{1 / \alpha} R^{(1-\alpha) / \alpha}$

$\mathrm{R}$ stands for the electrolyte resistance $\left(\mathrm{R}_{\mathrm{e}}\right)$ in the case of the gold electrode without coating and for the pore resistance $\left(\mathrm{R}_{\mathrm{p}}\right)$ in the case of the silicon nitride-coated electrode.

We found effective capacitances of $3.9 .10^{-8} \mathrm{~F} . \mathrm{cm}^{-2}$ and $8.9 .10^{-6} \mathrm{~F} . \mathrm{cm}^{-2}$ for coated and uncoated gold respectively, corresponding to $0.44 \%$ of accessible surface of the electrode at the bottom of through-pores. When considering the pore resistance value of $280 \Omega \mathrm{cm}^{2}$ and the 
thickness of the layer $(30 \mathrm{~nm})$, the accessible surface of the electrode determined by Brug allows us to calculate an electrolyte resistivity value inside the through-pores of $4.210^{4} \Omega \mathrm{cm}$. This value is rather high compared to the electrolyte resistivity in the rest of the cell (around 7 $\Omega \mathrm{cm}$ ), probably due to a lower ionic concentration in the pores than in the solution expected for systems of nanometric size.

The nanostructure of the layeris clear from STEM-HAADF images acquired in plan-view mode [Figure 6]. The diameter of pores was estimated with a good precision and is comprised between 0.5 and $2.0 \mathrm{~nm}$. Additionally, the porous surface is estimated from such images by applying an intensity threshold which corresponds to the absence of the nitride layer: the obtained valueis between $1 \%$ and $2 \%$ of the total surface. Since the fraction of pores which reach the electrode cannot be measured in plan-view observation, the porous surface calculated from STEM acquisition is certainly higher than the accessible surface of the electrode.

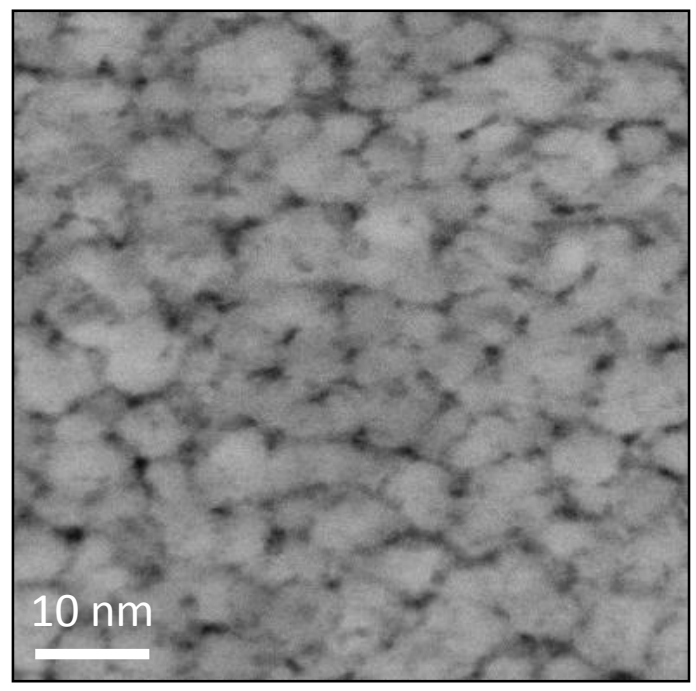


Figure 6 - HAADF-STEM image of $30 \mathrm{~nm}$ SiNx deposited on a silicon nitride commercial membrane. The pores appear darker than the solid nitride.

\subsection{Inhomogeneity in the thickness direction}

The impedance of the non-through-pores is described by the Young model. The resistivity of the layer decreases exponentially from the substrate interface to the upper layer surface in contact with the electrolyte (equation 5). Samples of different thicknesses were deposited by magnetron sputtering. Thus, the intrinsic resistivity is equivalent for all these layers. The following figure [Figure 7] presents the resistivity profiles obtained from the Young model for these samples normalized to the intrinsic resistivity.Error bars were estimated from the study of the reproducibility and homogeneity of the deposition. Indeed, several samples (up to 9) with the same thickness and from the same deposition conditions were measured by EIS and fitted with the same model as previously. The resistivity values obtained from the fit were compared in order to give a standard deviation for the resistivity parameter and to provide the error bars presented in figure 7. For each depth value, a gap separates the profiles of the thinnest layers $(10$ and $20 \mathrm{~nm}$ ) from the others (30 to $100 \mathrm{~nm})$, while the profiles seem superimposed between 30 and $100 \mathrm{~nm}$. Higher values of resistivity for thicker layers at a given depth could mean that the ionic concentration in the pores is lower. Increasing the thickness of the layer from 20 to $30 \mathrm{~nm}$ appears to block the ions' access to the electrode. 


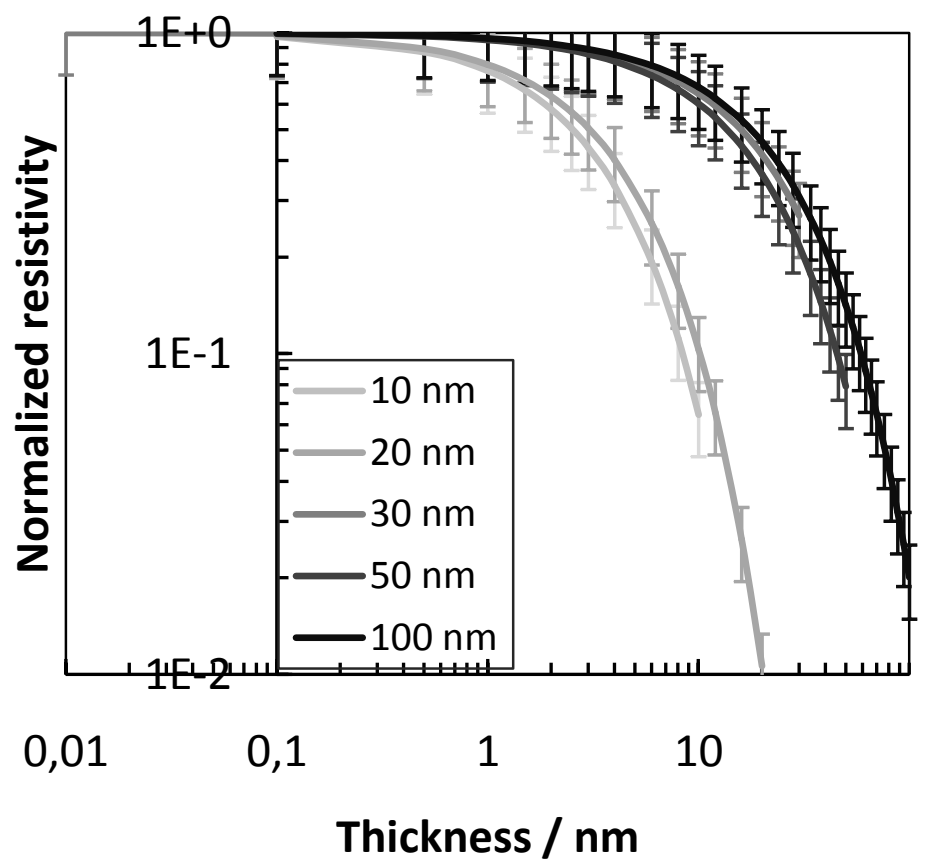

Figure 7 - Resistivity normalized by the intrinsic resistivity $\rho_{0}$ vs depth $x$ in log-log representation for layers of different thicknesses. The variable $e$ is 0 at the electrode and is equal to the value of the total thickness at the surface. These profiles were obtained from the Young model used in the fitting of the experimental impedance spectra. Error bars were added with respect to the reproducibility of the measurements.

This specific area near the substrate highlighted by EIS was investigated using TEM. The cross section bright-field observation of an FIB-prepared lamella from a $60 \mathrm{~nm}$ SiNx layer is presented in the following figure [Figure 8]. In this mode of acquisition, the voids or pores in the layer appear in lighter shades than the matter. The layer seems to be particularly inhomogeneous in the thickness direction. Indeed, at least three areas of different porosity seem to be distinguished across the thickness. The first $10 \mathrm{~nm}$ exhibit a dense nanostructure 
while the $10 \mathrm{~nm}$ to $30 \mathrm{~nm}$ area seems highly porous. From $30 \mathrm{~nm}$ to $60 \mathrm{~nm}$, the pores appear fewer. This TEM observation qualitatively confirms the discontinuity of pores ascertained from impedance measurements between 20 and $30 \mathrm{~nm}$, moving from a highly porous zone to a less porous zone.

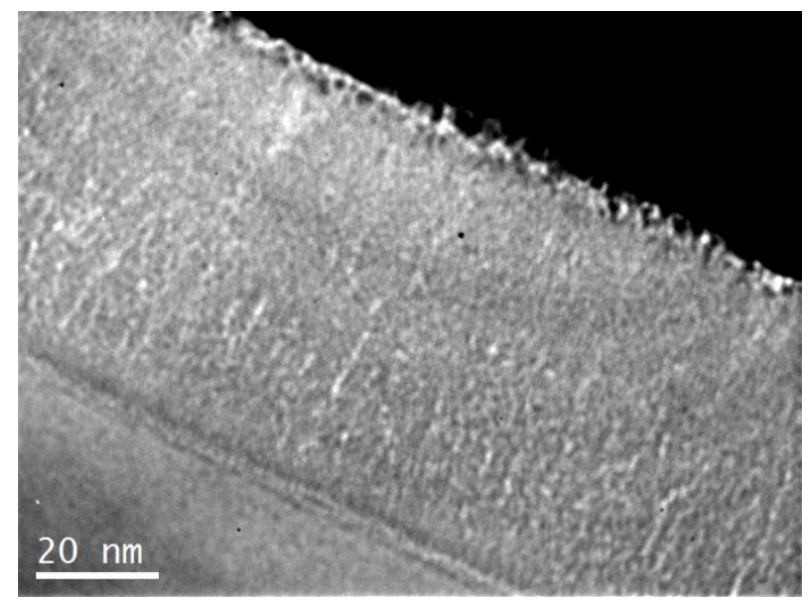

Figure 8 - TEM image in bright-field mode of a cross section of a $60 \mathrm{~nm} \mathrm{SiNx}$ layer. The pores appear brighter than the layer.

\section{Conclusions}

This study shows that impedance spectroscopy is a technique well suited to giving a global description of nanometer-scale pores in silicon nitride thin layers. Quantitative physical parameters are obtained by means of EIS, such as the intrinsic resistivity and the permittivity of the SiNx layer, the electrolyte resistivity in the through-pores and the accessible electrode surface area at the bottom of the pores. The layer is represented by an equivalent model composed of a Young impedance representing non-through-pores in parallel with the charge 
transfer at the bottom of the through-pores. The impregnation of the non-through-pores of the layer by the electrolyte is described by an exponential gradient of resistivity. The quantification of the accessible electrode fraction was realized using the Bruget al. formula [21] with the parameters of the electrical double layer and gives a value of accessible electrode area of $0.44 \%$ for a $30 \mathrm{~nm}$ SiNx layer deposited on gold.A STEM HAADF observation in plan view of the layer was used to determine a diameter of the pores ofbetween 0.5 and $2.0 \mathrm{~nm}$ and showedan upper value of $2 \%$ for the global porosity, compatible with the accessible surface area determined by EIS.

Additionally, the representation of the resistivity profile for layers with different thicknesses highlighted a specific area in the layers near the electrode. This result was confirmed by TEM bright-field observation of the cross section of a $60 \mathrm{~nm}$ layer showing discontinuous pores in the layer.

\section{Acknowledgements}

The authors gratefully acknowledge the support of Saint-Gobain Recherche (Aubervilliers, France), the "Laboratoire Interfaces et SystèmesElectrochimiques" (UMR 8235, Paris, France), the "Laboratoire de Physique des Solides" (UMR 8502, Orsay, France)and the ANR - "Programmeinvestissementd'avenir" with the Equipex TEMPOS-NANOTEM (for the FIB preparation). 


\section{References}

[1] K.H. Zaininger, C. Wang, Thin film dielectric materials for microelectronics, Proceedings of the IEEE, 57 (1969),p. 1564-1570, http://dx.doi.org/10.1109/PROC.1969.7337.

[2] P.H. Lissberger, Optical Applications of dielectric thin films, Rep. Prog.Phys., 33 (1970), p. 197, http://dx.doi.org/10.1088/0034-4885/33/1/305.

[3] H. Bach, D. Krause, Thin Films on Glass, Springer-Verlag Berlin Heidelberg, New-York (2003), http://dx.doi.org/10.1007/978-3-662-03475-0.

[4] M.J. Powell, Amorphous silicon-silicon nitride thin-film transistors, Appl. Phys. Lett., 38 (1981),p. 794,http://dx.doi.org/10.1063/1.92166.

[5] J.R. Elmiger, Recombination at the silicon nitride/silicon interface, J. Vac. Sci. Technol. A, 15 (1997),p.2418,http://dx.doi.org/10.1116/1.580757.

[6] Y.-C. Jeon, H.-Y.Lee, S.-K.Joo, I-V characteristics of electron-cyclotron-resonance plasma-enhanced chemical-vapor-deposition silicon nitride thin films, J. Appl. Phys., 75 (1994), p. 979,http://dx.doi.org/10.1063/1.356455.

[7] S.A. Awan, R.D. Gould, S. Gravano, Electrical conduction processes in silicon nitride thin films prepared by r.f. magnetron sputtering using nitrogen gas, Thin Solid Films, 356 (1999), p. 456-460, http://dx.doi.org/10.1016/S0040-6090(99)00550-7.

[8] J.H. Kim, K.W. Chung, Microstructure and properties of silicon nitride thin films deposited by reactive bias magnetron sputtering, J. Appl. Phys., 83 (1998), p. 5831, http://dx.doi.org/10.1063/1.367440.

[9] S. Ahn, J. Lee, H. Kim, J. Kim, A study on the quantitative determination of throughcoating porosity in PVD-grown coatings, Appl. Surf. Sci., 233 (2004), p. 105114,http://dx.doi.org/10.1016/i.apsusc.2004.03.213.

[10] M. Ruske, G. Bräuer, J. Pistner, J. Szczyrbowski, M. Weigert, Properties of $\mathrm{SiO}_{2}$ and $\mathrm{Si}_{3} \mathrm{~N}_{4}$ layers deposited by MF twin magnetron sputtering using different target materials, Thin Solid Films, 351 (1999), p. 158-163, http://dx.doi.org/10.1016/S0040-6090(99)00157-1. 
[11] A.-T. Tran, F. Huet, K. Ngo, P. Rousseau, Artefacts in electrochemical impedance measurement in electrolytic solutions due to the reference electrode, Electrochim. Acta., 56 (2011), p. 8034-8039, http://dx.doi.org/10.1016/i.electacta.2010.12.088.

[12] L. Young, Anodic oxide films. Part 4.-The interpretation of impedance measurements on oxide coated electrodes on niobium, Trans. Faraday Soc., 51 (1955), p. 1250-1260, http://dx.doi.org/10.1039/TF9555101250.

[13] B. Hirschorn, M.E. Orazem, B. Tribollet, V. Vivier, I. Frateur, M. Musiani, ConstantPhase-Element Behavior Caused by Resistivity Distributions in Films I. Theory, J. Electrochem. Soc., 157 (2010), p. C452, http://dx.doi.org/10.1149/1.3499564.

[14] B. Hirschorn, M.E. Orazem, B. Tribollet, V. Vivier, I. Frateur, M. Musiani, ConstantPhase-Element Behavior Caused by Resistivity Distributions in Films II. Applications, J. Electrochem.Soc., 157 (2010), p. C458, http://dx.doi.org/10.1149/1.3499565.

[15] C.A. Schiller, W. Strunz, The evaluation of experimental dielectric data of barrier coatings by means of different models, Electrochim. Acta.,46 (2001), p. 36193625,http://dx.doi.org/10.1016/S0013-4686(01)00644-2.

[16] A.S. Nguyen, M. Musiani, M.E. Orazem, N. Pébère, B. Tribollet, V. Vivier, Impedance analysis of the distributed resistivity of coatings in dry and wet conditions, Electrochim. Acta.,179 (2015), p. 452-459, http://dx.doi.org/10.1016/i.electacta.2015.02.109.

[17] K.S. Cole, R.H. Cole, Dispersion and Absorption in Dielectrics I. Alternating Current Characteristics, J. Chem. Phys., 9 (1941), p. 341, http://dx.doi.org/10.1063/1.1750906.

[18] M. Benoit, C. Bataillon, B. Gwinner, F. Miserque, M.E. Orazem, C.M. Sánchez-Sánchez, B. Tribollet, V. Vivier, Comparison of different methods for measuring the passive film thickness on metals, Electrochim. Acta., 201 (2016), p. 340-347, http://dx.doi.org/10.1016/i.electacta.2015.12.173.

[19] S.M. Sze, Current Transport and Maximum Dielectric Strength of Silicon Nitride Films, J. Appl. Phys., 38 (1967), p. 2951,http://dx.doi.org/10.1063/1.1710030.

[20] M. Vila, C. Prieto, R. Ramirez, Electrical behavior of silicon nitride sputtered thin films, Thin Solid Films, 459 (2004), p. 195-199,http://dx.doi.org/10.1016/i.tsf.2003.12.082. 
[21] G.J. Brug, A.L.G. Van den Eeden, M. Sluyters-Rehbach, J.H. Sluyters, The analysis of electrode impedance complicated by the presence of a constant phase element, J. Electroanal. Chem., 176 (1984), p. 275-295, http://dx.doi.org/10.1016/S00220728(84)80324-1. 